\title{
Investigação das atividades alelopática e antimicrobiana de Mikania laevigata (Asteraceae) obtida de cultivos hidropônico e tradicional
}

\author{
Leopoldo Baratto, ${ }^{1}$ Karen Luise Lang, ${ }^{2}$ Danielli Cássia Vanz, ${ }^{3}$ Flávio Henrique Reginatto, ${ }^{4}$ \\ Jorge Barcelos Oliveira, ${ }^{5}$ Miriam Falkenberg $*, 4$ \\ ${ }^{\text {I} C u r s o ~ d e ~ G r a d u a c ̧ a ̃ o ~ e m ~ F a r m a ́ c i a, ~ C e n t r o ~ d e ~ C i e ̂ n c i a s ~ d a ~ S a u ́ d e, ~ C a m p u s ~ T r i n d a d e, ~ U n i v e r s i d a d e ~ F e d e r a l ~ d e ~}$ \\ Santa Catarina, 88040-970 Florianópolis-SC, Brasil, \\ ${ }^{2}$ Programa de Pós-Graduação em Farmácia, Centro de Ciências da Saúde, Campus Trindade, Universidade \\ Federal de Santa Catarina, 88040-970 Florianópolis-SC, Brasil, \\ ${ }^{3}$ Curso de Farmácia, Universidade de Passo Fundo, 99001-970 Passo Fundo-RS, Brasil, \\ ${ }^{4}$ Departamento de Ciências Farmacêuticas, Centro de Ciências da Saúde, Campus Trindade, Universidade \\ Federal de Santa Catarina, 88040-970 Florianópolis-SC, Brasil, \\ ${ }^{5}$ Departamento de Engenharia Rural, Centro de Ciências Agrárias, Campus Itacorubi, Universidade Federal de \\ Santa Catarina, 88040-900 Florianópolis-SC, Brasil
}

\begin{abstract}
RESUMO: Os extratos etanólicos de folhas de guaco (Mikania laevigata) cultivado tradicionalmente no solo ou por hidroponia foram avaliados quanto às atividades alelopática e antimicrobiana. Para a atividade alelopática foi utilizado o ensaio de inibição da germinação de sementes de alface (Lactuca sativa), enquanto que para a atividade antimicrobiana utilizouse a técnica de difusão em disco. Observou-se um notável efeito alelopático dos extratos de ambos os cultivos, em especial do extrato etanólico do guaco tradicional, que mesmo na menor concentração testada inibiu completamente a germinação das sementes. Nenhum dos extratos etanólicos do guaco apresentou atividade antibacteriana significativa para as linhagens de Staphylococcus aureus, Escherichia coli, Pseudomonas aeruginosa, Enterococcus faecalis e Enterococcus faecium.
\end{abstract}

Unitermos: Mikania laevigata, alelopatia, atividade antimicrobiana, hidroponia, cultivo tradicional.

\begin{abstract}
Investigation of the allelopathic and antimicrobial activities of Mikania laevigata (Asteraceae) obtained in hydroponic and traditional cultivars". The ethanolic extract of "guaco" (Mikania laevigata) traditionally cultivated in the soil or in a hydroponic system were tested for allelopathic and antimicrobial activities. Allelopathic activity was evaluated by the inhibition of germination assay using lettuce seeds, and antimicrobial activity by the disc diffusion assay. A notable allelopathic effect was observed for both extracts, although a more expressive activity of traditional "guaco" was verified, since the inhibition of seeds germination was $100 \%$ even in the lower concentration. None ethanolic extract of "guaco" presented significant antimicrobial activity against Staphylococcus aureus, Escherichia coli, Pseudomonas aeruginosa, Enterococcus faecalis and Enterococcus faecium.
\end{abstract}

Keywords: Mikania laevigata, allelopathy, antimicrobial activity, hydroponics, traditional cultivation.

\section{INTRODUÇÃO}

O gênero Mikania, pertencente à família Asteraceae, possui mais de 430 espécies, sendo que cerca de 150 ocorrem no Brasil (Hind, 1993; Brandão et al., 2006; Agra et al., 2007 \& 2008; Brandão et al., 2008). Mikania laevigata Schultz Bip. ex Baker, conhecida popularmente como "guaco", é utilizada pelas suas propriedades antisséptica, expectorante, antiasmática e antirreumática (Simões et al., 1988) e por sua semelhança morfológica com Mikania glomerata é freqüentemente confundida com esta espécie. Ambas são subarbustos de hábito trepador, apresentando caule cilíndrico, folhas opostas e de contorno oval, sendo que os capítulos dispõem-se em forma de glomérulos (Gilbert et al., 2005).

No gênero Mikania relata-se a presença de taninos, saponinas, óleo essencial contendo diterpenos e sesquiterpenos (Silva Júnior et al., 1994; Martins et al., 1998), além de cumarina, ácidos hidroxicinâmico 
e metilcaurenóico (Fierro et al., 1999; TalebContini et al., 2006), e também ácidos caurenóico e cinamoilgrandiffórico (Davino et al., 1989; Bertolucci et al., 2006; Pedroso et al., 2008). Diterpenos derivados do ácido caurenóico foram detectados em ambas as espécies, porém, pela análise em CLAE, foi observado que eles ocorrem em maiores concentrações em $M$. glomerata (Bertolucci et al., 2006). O óleo essencial de $M$. laevigata é constituído por sesquiterpenos representados por $\beta$-cariofileno, germacreno-D e biciclogermacreno (Limberger et al., 1998), enquanto que o óleo essencial de M. glomerata contém sesquiterpenos altamente oxigenados, como espatulenol e óxido de cariofileno (Limberger et al., 2001).

As cumarinas são responsáveis pelo aroma característico do guaco e sua concentração nas folhas pode variar em função de vários fatores, como os níveis de radiação solar e fotoperíodos (Castro et al., 2006). Cerca de $0,5 \%$ de cumarina foi encontrada nas folhas de $M$. glomerata e de 1,1 até $2,6 \%$ nas folhas de $M$. laevigata processadas da mesma maneira (Gilbert et al., 2005). Foi observado que quando as partes aéreas de $M$. glomerata foram irradiadas com raios gama, o conteúdo de cumarina aumentou, enquanto que a concentração de ácido $o$-cumárico diminuiu (Peregrino \& Leitão, 2005).

A notável versatilidade do cultivo hidropônico, aliada aos excelentes resultados que se podem obter nos mais variados lugares, faz dele o sistema ideal para se adotar em uma ampla gama de condições diferentes (Douglas, 1987). Em alguns casos, o solo pode carecer de nutrientes ou ter uma estrutura pobre, e ainda a presença de insetos reduz consideravelmente as produções de forma tradicional (Resh, 1996). As vantagens do cultivo hidropônico incluem produção de melhor qualidade, crescimento vegetal mais rápido, economia de tempo $\mathrm{e}$ trabalho, custos menores, maior produtividade por área, equilíbrio nutricional, melhor aproveitamento da água, entre outros (Teixeira, 1996; Douglas, 1987; Resh, 1996; Alberoni, 1998; Delfín et al., 2000).

Em trabalhos anteriores de nosso grupo, relacionados ao cultivo hidropônico de plantas medicinais, verificamos vantagens deste sistema na produção de biomassa de Mikania laevigata (Scalco et al., 2002; Dinon et al., 2003; Baratto et al., 2006). O objetivo do presente trabalho foi avaliar o potencial alelopático e antimicrobiano dos extratos etanólicos das folhas de Mikania laevigata obtida por dois tipos de cultivo.

\section{MATERIAL E MÉTODOS}

\section{Material vegetal}

Mikania laevigata foi cultivada nas instalações do Laboratório de Agricultura Irrigada e Hidroponia (LabHidro) no Centro de Ciências Agrárias (CCA) da Universidade Federal de Santa Catarina (Florianópolis,
Brasil). As estacas foram preparadas a partir de exemplar autêntico, identificado por Mara Rejane Ritter (exsicata FLOR29367, Departamento de Botânica, UFSC). Uma parte das estacas foi transplantada para o solo, constituindo o grupo controle (guaco tradicional, cultivado no solo) e as demais foram transferidas para uma bancada de hidroponia e receberam uma solução nutritiva balanceada de acordo com a condutividade, que foi mantida entre 1,2 a $2,2 \mathrm{mS} / \mathrm{cm}$. As folhas do guaco de ambos os cultivos foram coletadas no mês de outubro de 2005, quando apresentavam grande desenvolvimento e produção de biomassa.

\section{Preparo dos extratos}

As folhas de ambos os experimentos foram secas em estufa de ar circulante, a cerca de $30{ }^{\circ} \mathrm{C}$, trituradas em moinho de facas e submetidas a extração por maceração em etanol (EtOH) P.A. (96\%) na proporção de 1:10 (m/V) durante sete dias. O extrato foi filtrado e concentrado em rotavapor sob temperatura inferior a $60{ }^{\circ} \mathrm{C}$ até secura total dos extratos.

\section{Ensaio da inibição germinativa (alelopatia)}

Os extratos secos de guaco hidropônico e tradicional foram redissolvidos em etanol P.A., obtendose soluções em concentrações de 5, 10, 15 e $20 \mathrm{mg} /$ $\mathrm{mL}$. Foram aplicados $3 \mathrm{~mL}$ de cada uma das soluções ou $3 \mathrm{~mL}$ de água destilada ou etanol P.A. 96\% sobre discos de papel de filtro colocados em placas de Petri, deixando-se evaporar completamente o solvente. Em seguida, todos os discos foram umedecidos com $3 \mathrm{~mL}$ de água destilada e sobre a superfície de cada um foram distribuídas 20 sementes de alface (Lactuca sativa L., variedade Boston Branca). O ensaio foi realizado em triplicata, sendo monitorado por dois controles em que o disco de papel foi anteriormente impregnado com água destilada (controle "branco") ou EtOH P.A. (controle do solvente utilizado na extração e na diluição do extrato seco). As placas foram recobertas com filme plástico, expostas à luz natural e mantidas à temperatura ambiente. A contagem das sementes que germinaram deu-se em intervalos de 24, 48, 72 e 96 horas após a distribuição das sementes e baseou-se na emissão de radícula (Figura 1). Calculou-se a percentagem de inibição da germinação das sementes em relação aos controles e a significância da inibição da germinação foi avaliada pelo teste do qui-quadrado $\left(\chi^{2}\right)$ (tabela de contingência $2 \times 2$ ), com correção de Yates, sendo que valores iguais ou superiores a 3,84 foram considerados significativos $(\alpha=0,05)$ (Centeno, 1990).

\section{Ensaio da atividade antimicrobiana}

Foi realizada uma triagem da atividade antibacteriana frente a linhagens padrão ATCC de 


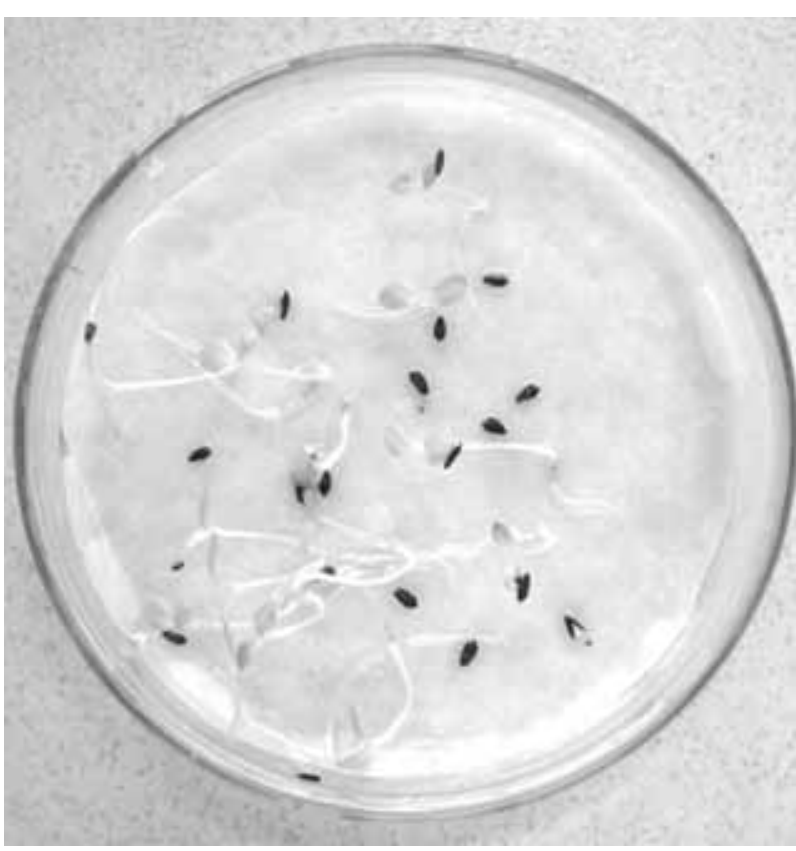

Figura 1. Sementes de alface germinadas na placa controle com água destilada.

Staphylococcusaureus(25923), Escherichiacoli(25992), Pseudomonas aeruginosa (27853), Enterococcus faecalis (29212) e Enterococcus faecium (10541), empregando-se a técnica de difusão de disco conforme as normas preconizadas pelo NCCLS (National Committee for Clinical Laboratory Standard, 2004). O meio de cultura utilizado para o ensaio antibacteriano foi ágar Müller-Hinton (Merck) recém-preparado e submetido previamente ao teste de esterilidade. Em seguida foram aplicados os discos de papel de filtro impregnados com volume definido das soluções etanólicas dos extratos (20 $\mu \mathrm{L}$ ), bem como os discos de fármacos antimicrobianos (ampicilina, amicacina, cloranfenicol e ceftadizima) em concentração definida para o controle de qualidade do ensaio. As concentrações testadas dos extratos de guaco foram de 1,$25 ; 2,5 ; 10,25,50$ e $100 \mathrm{mg} / \mathrm{mL}$. Os extratos foram diluídos em água esterilizada e aplicados em discos de papel de filtro de $6 \mathrm{~mm}$ de diâmetro. Após a aplicação dos discos, as placas foram incubadas em estufa a $35 \pm 1{ }^{\circ} \mathrm{C}$ e após 18 horas de incubação foi realizada a leitura dos diâmetros dos halos de inibição.

\section{RESULTADOS E DISCUSSÃO}

\section{Inibição da germinação (alelopatia)}

Observou-se um notável efeito alelopático de ambos os extratos, considerado estatisticamente significativo. O extrato do guaco tradicional inibiu completamente a germinação das sementes em todas as concentrações testadas, enquanto que o extrato do guaco hidropônico teve $53 \%$ das sementes inibidas na concentração de $5 \mathrm{mg} / \mathrm{mL}$ e $100 \%$ de inibição da germinação nas demais concentrações (Tabela 1). Verificou-se uma maior atividade alelopática do extrato etanólico do guaco tradicional, em comparação ao guaco hidropônico, uma vez que o primeiro inibiu completamente a germinação das sementes mesmo na

Tabela 1. Comparação do número de sementes de alface que germinaram (valores acumulados) em 24, 48, 72 e 96 horas. Os grupos teste foram expostos a extratos de guaco hidropônico $(\mathrm{GH})$ ou tradicional $(\mathrm{GT})$ e os grupos controles, a água $\left(\mathrm{H}_{2} \mathrm{O}\right)$ ou etanol $(\mathrm{EtOH})$.

\begin{tabular}{|c|c|c|c|c|c|c|c|c|c|}
\hline \multirow{2}{*}{$\begin{array}{c}\mathrm{GH} \\
(\mathrm{mg} / \mathrm{mL})\end{array}$} & \multicolumn{4}{|c|}{$\begin{array}{l}\mathrm{N}^{o} \text { de sementes germinadas em períodos de } \\
\text { tempo }\end{array}$} & \multirow{2}{*}{$\begin{array}{c}\mathrm{GT} \\
(\mathrm{mg} / \mathrm{mL})\end{array}$} & \multicolumn{4}{|c|}{$\begin{array}{c}\mathrm{N}^{\mathrm{o}} \text { de sementes germinadas em períodos de } \\
\text { tempo }\end{array}$} \\
\hline & $24 \mathrm{~h}$ & $48 \mathrm{~h}$ & $72 \mathrm{~h}$ & $\overline{96 \mathrm{~h}}$ & & $24 \mathrm{~h}$ & $48 \mathrm{~h}$ & $72 \mathrm{~h}$ & $96 \mathrm{~h}$ \\
\hline 5 & 0 & 0 & 2 & 9 & 5 & 0 & 0 & 0 & 0 \\
\hline 10 & 0 & 0 & 0 & 0 & 10 & 0 & 0 & 0 & 0 \\
\hline 15 & 0 & 0 & 0 & 0 & 15 & 0 & 0 & 0 & 0 \\
\hline 20 & 0 & 0 & 0 & 0 & 20 & 0 & 0 & 0 & 0 \\
\hline \multicolumn{10}{|c|}{ Controles } \\
\hline $\mathrm{H}_{2} \mathrm{O}$ & 10 & 15 & 17 & 17 & $\mathrm{EtOH}$ & 11 & 15 & 17 & 17 \\
\hline
\end{tabular}

Tabela 2. Percentagem de inibição da germinação de sementes de alface dos extratos de guaco hidropônico e tradicional (* valores estatisticamente diferentes em relação aos controles, conforme teste do qui-quadrado, $\alpha=0,05$ ).

\begin{tabular}{|c|c|c|}
\hline Concentração (mg/mL) & $\begin{array}{l}\text { \% de inibição da germinação de sementes pelo } \\
\text { extrato de guaco hidropônico }\end{array}$ & $\begin{array}{l}\% \text { de inibição da germinação de sementes pelo } \\
\text { extrato de guaco tradicional }\end{array}$ \\
\hline 5 & $53 *$ & $100 *$ \\
\hline 10 & $100 *$ & $100 *$ \\
\hline 15 & $100 *$ & $100 *$ \\
\hline 20 & $100 *$ & $100 *$ \\
\hline
\end{tabular}


menor concentração, conforme pode ser observado na tabela 2 .

A interação entre plantas consorciadas é bastante explorada em cultivos convencionais, trazendo inúmeros benefícios do ponto de vista agronômico, favorecendo a produtividade (França, 2004). Através desta interação, chamada de alelopatia, um vegetal compete com outro, provavelmente para assegurar o fornecimento de água, luz e nutrientes (Poser \& Mentz, 2004). A alelopatia envolve uma cadeia complexa de comunicações químicas entre as plantas (Inderjit \& Dakshini, 1995) e é um importante mediador da dinâmica populacional, determinando o padrão e a densidade da vegetação, em sistemas naturais e cultivados (Souza Filho, 2006). Os efeitos alelopáticos são sempre mediados por substâncias que pertencem a diferentes classes de metabólitos secundários, tais como fenóis, derivados dos ácidos cinâmico e benzóico, flavonóides, cumarinas, taninos, terpenos, alcalóides e poliacetilenos. No entanto, é difícil identificar qual desses grupos de metabólitos secundários é o principal responsável pela atividade alelopática (Inderjit \& Dakshini, 1995).

Independentemente dos tipos de cultivos, $M$. laevigata mostrou-se uma planta promissora do ponto de vista agroecológico. Propriedades alelopáticas já foram descritas para uma outra espécie conhecida como guaco (Dias et al., 2005). Shao et al. (2005) demonstraram que o extrato aquoso de $M$. micrantha inibiu a germinação e o crescimento de algumas plantas, até mesmo quando resíduos do extrato foram incorporados na superfície do solo. Foram identificados alguns sesquiterpenos com significativa atividade alelopática; eles podem ser depositados diretamente no solo pela água da chuva ou gradualmente liberados durante a decomposição das folhas, afetando o crescimento de plantas vizinhas e colaborando para que $M$. micrantha torne-se uma espécie dominante em novos ecossistemas. A falta de predadores naturais desta espécie, como insetos fitófagos e fungos, permite que ela se dissemine rapidamente, provocando desequilíbrios ecológicos. Foram identificados alguns compostos responsáveis pelo efeito alelopático de espécies de Asteraceae: cumarinas, ácido trans-cinâmico, ácidos o-cumárico e $p$-cumárico, demonstrando que muitas espécies desta família possuem potencial herbicida (Chon et al., 2003). Os extratos aquosos e etanólicos de Baccharis trimera (Less.) DC. (carqueja) e Hypericum spp por exemplo, possuem substâncias que apresentam elevada inibição da germinação das sementes de alface (Carreira et al., 2005; Fritz et al., 2007).

A diferença na potência alelopática dos extratos obtidos a partir dos dois tipos de cultivos pode ser explicada pela influência dos diversos fatores ambientais a eles relacionados, como a temperatura, a intensidade luminosa, a textura do solo e microrganismos presentes, e ainda a disponibilidade de água e nutrientes (Gatti et al., 2004), variando conforme o ambiente no qual o vegetal se desenvolve e o tipo de cultivo empregado (Simões \& Spitzer, 2004). No sistema hidropônico, o aporte de água e nutrientes é constante, o que freqüentemente contribui para o crescimento e produção de biomassa, mas na ausência de substrato (solo) a exposição a microrganismos é reduzida, o que pode diminuir a produção de certos metabólitos secundários.

Recentemente, estudos vêm sendo realizados, focados no manejo e no controle das ervas daninhas, na tentativa de diminuir o uso de herbicidas comerciais, seja através da utilização da alelopatia, por meio da rotação de culturas, sistemas adequados de semeadura entre espécies e entresafras, além de sistemas agroecológicos (Gatti et al., 2004). Assim, o cultivo de Mikania laevigata pode vir a se estabelecer como uma nova alternativa para o manejo de ervas daninhas, vantagem que se somaria ao próprio valor econômico como planta medicinal.

\section{Atividade antimicrobiana}

Não houve formação de halo de inibição com nenhum dos extratos de $M$. laevigata, de modo que nas concentrações testadas não houve atividade antibacteriana significativa para as linhagens de $S$. aureus (25923), E. coli (25992), P. aeruginosa (27853), E. faecalis (29212) e E. faecium (10541). Estes resultados são, de certa forma, inesperados, considerando o uso popular da espécie como antisséptico e outros estudos publicados com espécies de guaco. A cumarina é considerada uma das substâncias responsáveis pela atividade antimicrobiana do guaco (dos Santos et al., 1996) e sua presença já foi comprovada em M. laevigata. Em outro estudo com esta espécie, comprovou-se atividade inibitória do extrato etanólico sobre o crescimento e a adesão celular de Streptococcus mutans, um grupo de microorganismos associados às cáries dentais. Acredita-se que os ácidos cupressênico, diterpênico e caurenóico possam ser responsáveis por esta atividade (Yatsuda et al., 2005).

O óleo essencial de outra espécie de guaco, $M$. glomerata, exibiu uma forte atividade contra Candida albicans. Dentre os componentes do óleo essencial, alguns apresentaram atividade antimicrobiana, incluindo 1,8-cineol, limoneno, linalol, geranial, germacreno-D e mentol (Duarte et al., 2005). As frações obtidas em diclorometano, acetato de etila e n-butanol a partir de $M$. lanuginosa e o ácido caurenóico apresentaram atividade antimicrobiana frente a bactérias Grampositivas (Staphylococcus aureus e S. epidermidis), mas foram inativos contra bactérias Gram-negativas (Pseudomonas aeruginosa, Escherichia coli e Bacillus cereus) (Rios et al., 2000). O extrato etanólico das folhas de $M$. hirsutissima não exibiu atividade antibacteriana contra $E$. coli, no entanto mostrou-se ativo contra $S$. aureus (Brasileiro et al., 2006).

A avaliação da atividade frente a outras espécies de microrganismos contribuirá para uma 
melhor definição do perfil de atividade antimicrobiana de Mikania laevigata e de eventuais diferenças entre extratos obtidos a partir de diferentes formas de cultivo.

\section{AGRADECIMENTOS}

À Profa. Dra. Mara Rejane Ritter (Depto. de Botânica, UFRGS) pela identificação do material vegetal, ao Programa Institucional de Bolsas de Iniciação Científica (PIBIC/CNPq/UFSC) pela bolsa concedida ao autor L. Baratto; à Fundação de Apoio à Pesquisa do Estado do Rio Grande do Sul (FAPERGS, Edital PROADE 2) e à Fundação de Apoio à Pesquisa do Estado de Santa Catarina (FAPESC, Edital Universal 2003), pelos financiamentos concedidos.

\section{REFERÊNCIAS}

Agra MF, França PF, Barbosa-Filho JM 2007. Synopsis of the plants known as medicinal and poisonous in Northeast of Brazil. Rev Bras Farmacogn 17: 114140.

Agra MF, Silva KN, Basílio IJLD, França PF, Barbosa-Filho JM 2008. Survey of medicinal plants used in the region Northeast of Brazil. Rev Bras Farmacogn 18: 472-508.

Alberoni RB 1998. Hidroponia: como instalar e manejar o plantio de hortaliças dispensando o uso do solo. São Paulo: Nobel.

Baratto L, Oliveira JB, Falkenberg M 2006. Análise fitoquímica de plantas medicinais obtidas por cultivo hidropônico e tradicional. XVI Seminário de Iniciação Científica da UFSC. Florianópolis, Brasil.

Bertolucci SKV, Pinto JEBP, Pereira ABD, Oliveira AB, Braga FC 2006. Isolamento de marcadores químicos e obtenção de perfis cromatográficos por CLAE para Mikania glomerata Sprengel e Mikania laevigata Schultz Bip. ex Baker. XIX Simpósio de Plantas Medicinais, Salvador, Brasil.

Brandão MGL, Cosenza GP, Moreira RA, Monte-Mor RLM 2006. Medicinal plants and other botanical products from the Brazilian Official Pharmacopoeia. Rev Bras Farmacogn 16: 408-420.

Brandão MGL, Zanetti NNS, Oliveira GRR, Goulart LO, Monte-Mor RLM 2008. Other medicinal plants and botanical products from the first edition of the Brazilian Official Pharmacopoeia. Rev Bras Farmacogn 18: 127-134.

Brasileiro BG, Pizziolo VR, Raslan DS, Jamal CM, Silveira D 2006. Antimicrobial and cytotoxic activities screening of some Brazilian medicinal plants used in Governador Valadares district. Rev Bras Cienc Farmac 42: 195-202.

Carreira RC, Torres LMB, Young MCM, Zaidan LB 2005. Efeitos alelopáticos de extratos de Baccharis trimera na germinação de sementes de alface. V Reunión de la Sociedad Latinoamericana de Fitoquímica, Montevideo, Uruguai.

Castro EM, Pinto JEBP, Bertolucci SKV, Malta MR, Cardoso MG, Silva FAM 2006. Coumarin contents in young
Mikania glomerata plants (Guaco) under different radiation levels and photoperiod. Acta Farm Bonaerense 25: 387-392.

Centeno AJ 1990. Curso de estatística aplicada à biologia. Brasil: Cegraf-UFG..

Chon SU, Kim YM, Lee JC 2003. Herbicidal potential and quantification of causative allelochemicals from several Compositae weeds. Weed Res 43: 444-450.

Davino SC, Giesbrecht AM, Roque NF 1989. Antimicrobial activity of kaurenoic acid derivates substitued on carbon- 15. Braz J Med Biol Res 22: 1127-1129.

Delfín AR, La Rosa MC, Rojas MH, Gutiérrez FF 2000. Manual práctico de hidroponía. Peru: Universidad Nacional Agraria La Molina.

Dias JFG, Círio GM, Miguel MD, Miguel OG 2005. Contribuição ao estudo alelopático de Maytenus ilicifolia Mart. ex Reiss., Celastraceae. Rev Bras Farmacogn 15: 220-223.

Dinon AZ, Schlosser R, Falkenberg M, Oliveira JLB, Ramos D 2003. Análise química de extratos de guaco (Mikania laevigata Schultz Bip ex Baker): comparação dos materiais vegetais obtidos por hidroponia e pelo cultivo tradicional. IV Jornada Catarinense de Planta Medicinais. Itajaí, 2003.

dos Santos TC, Tomassini TCB, Sanchez E, Cabral LM 1996 Estudo da atividade antimicrobiana de Mikania glomerata Sprengel. XIV Simpósio de Plantas Medicinais do Brasil. Florianópolis, Brasil.

Douglas JS 1987. Hidroponia: cultura sem terra. São Paulo: Nobel.

Duarte MCT, Figueira GM, Sartoratto A, Rehder VLG, Delarmelina C 2005. Anti-Candida activity of Brazilian medicinal plants. J Ethnopharmacol 97: 305-311.

Fierro IM, Silva AB, Lopes CS, Moura RS, Barja-Fidalgo C 1999. Studies on the anti-allergic activity of Mikania glomerata. J Ethnopharmacol 66: 19-24.

França SC 2004. Abordagens biotecnológicas para a obtenção de substâncias ativas. In: Simões CMO, Schenkel EP, Gosmann G, Mello JCP de; Mentz LA, Petrovick PR (Org.). Farmacognosia: da planta ao medicamento. 5.ed. Porto Alegre/Florianópolis: Editora da UFRGS / Editora da UFSC, cap. 7, p. 128.

Fritz D, Bernardi AP, Haas JS, Ascoli BM, Bordignon SAL, von Poser G 2007. Germination and growth inhibitory effects of Hypericum myrianthum and H. polyanthemum extracts on Lactuca sativa L. Rev Bras Farmacogn 17: 44-48.

Gatti AB, Perez SCJGA, Lima MIS 2004. Atividade alelopática de extratos aquosos de Aristolochia esperanzae O. Kuntze na germinação e no crescimento de Lactuca sativa L. e Raphanus sativus L. Acta Bot Bras 18: 459-472.

Gilbert B, Ferreira JLP, Alves LF 2005. Monografias de plantas medicinais brasileiras e aclimatadas. Curitiba: Abifito.

Hind DJN 1993. Kew Bull 48: 245-277.

Inderjit, Dakshini KMM 1995. On laboratory bioassays in allelopathy. Bot Rev 61: 29-44.

Limberger R, Suyenaga ES, Henriques ATC, Menut C, Verin P, Lamaty G, Bessiere JM 1998. Aromatic plants from Brazil. Part VI. Chemical composition of essential oils from three southern Brazilian species of Mikania 
(Asteraceae). J Essent Oil Res 10: 363-367.

Limberger RP, Aboy AL, Bassani VL, Moreno PRH, Ritter, MR, Henriques, AT 2001. Essential oils from four Mikania species (Asteraceae). J Essent Oil Res 13: 225-228.

Martins ER, Castro DM, Castellani DC, Dias JE 1998. Plantas medicinais. Viçosa: UFV.

National Committee for Clinical Laboratory Standards 2004. Performance standards for antimicrobial susceptibility testing. Approved standard M100-S14. NCCLS, Wayne, PA.

Pedroso APD, Santos SC, Steil AA, Deschamps F, Barison A, Campos F, Biavatti MW 2008. Isolation of syringaldehyde from Mikania laevigata medicinal extract and its influence on the fatty acid profile of mice. Rev Bras Farmacogn 18: 63-69.

Peregrino CAF, Leitão SG 2005. Chromatographical profiles of fluid extracts and tinctures obtained from Mikania glomerata Sprengel sterilized by gamma ray irradiation. Rev Bras Farmacogn 15: 237-242.

Poser GL, Mentz, LA 2004. Diversidade Biológica e Sistemas de Classificação. In: Simões CMO, Schenkel EP; Gosmann G, Mello JCP de, Mentz LA, Petrovick PR (Org.). Farmacognosia: da planta ao medicamento. 5.ed. Porto Alegre/Florianópolis: Editora da UFRGS / Editora da UFSC, cap. 4, p. 82.

Resh HM 1996. Cultivos hidropônicos. 4. ed. Espanha: MundiPrensa.

Rios EM, Silva RZ, Silva MZ, Leal LF, Miguel OG, Cechinel Filho V 2000. Atividade antibacteriana da Mikania lanuginosa DC (Asteraceae). XVI Simpósio de Plantas Medicinais do Brasil. Recife, Brasil.

Scalco GF, Oliveira JB, Falkenberg M 2002. Análise química e biológica do guaco: comparação entre amostras obtidas por hidroponia e pelo método tradicional. XII Seminário de Iniciação Científica da UFSC. Florianópolis, Brasil.

Shao H, Peng S, Wel X, Zhang D, Zhang, C 2005. Potential allelochemicals from invasive weed Mikania micrantha H.B.K. J Chem Ecol 31: 1657-1668.

Silva Júnior AA, Vizzoto VJ, Giorgi E, Macedo SG, Marques LF 1994. Plantas medicinais: caracterização e cultivo. Florianópolis: Epagri.

Simões CMO, Mentz LA, Schenkel EP, Irgang BE, Stehmann JR, 1988. Plantas da Medicina Popular do Rio Grande do Sul. Porto Alegre: UFRGS.

Simões CMO, Spitzer V 2004. Óleos Voláteis. In: Simões CMO, Schenkel EP; Gosmann G, Mello JCP de, Mentz LA, Petrovick PR (Org.). Farmacognosia: da planta ao medicamento. 5.ed. Porto Alegre/ Florianópolis: Editora da UFRGS / Editora da UFSC, cap. 18 , p. 475.

Souza Filho APS 2006. Proposta metodológica para análise da ocorrência de sinergismo e efeitos potencializadores entre aleloquímicos. Planta Daninha 24: 607-610.

Taleb-Contini SH, Santos PA, Veneziani RCS, Pereira AMS, França SC, Lopes NP, Oliveira DCR 2006. Differences in secondary metabolites from leaf extracts of Mikania glomerata Sprengel obtained by micropropagation and cuttings. Rev Bras Farmacogn 16 (Supl.): 596-598.

Teixeira NT 1996. Hidroponia: uma alternativa para pequenas áreas. Guaíba: Agropecuária.
Yatsuda R, Rosalen PL, Cury JA, Murata RM, Rehder VLG, Melo LV, Koo H 2005. Effects of Mikania genus plants on growth and cell adherence of mutans streptococci. J Ethnopharmacol 97: 183-189. 